

\title{
A New Polymer Electrolyte for Solid-State Quantum Dot Sensitized Solar
}

\author{
Cells \\ Ying Yang and Wenyong Wang* \\ Department of Physics \& Astronomy, University of Wyoming, Laramie, WY 82071, USA
}

Abstract: Liquid electrolytes in quantum dot sensitized solar cells (QDSSCs) cause device packaging and stability issues, and in this work a new type of solid-state electrolyte based on PEO-PVDF polymer blends with S/tetramethylammonium sulfate (S/TMAS) redox additive is investigated. UV-Vis and ionic conductivity measurements are performed to characterize the electrolytes' optical and electrochemical properties. QDSSCs are fabricated using the polymer electrolytes, and a possible additional redox process in the cells is proposed. The study shows that the PEO-PVDF polymer electrolyte with the S/TMAS redox additive can improve the solar cell incident photon-to-current conversion efficiency and stability. This research could shed light on the study of novel solid-state QDSSCs based on polymer electrolytes with further enhanced performance.

Keywords: Polymer Electrolyte, Redox Couple, Solar Cells, Stability

\footnotetext{
*Corresponding author. Tel.: +1 (307) 766-6523; Fax: +1 (307) 766-2652; E-mail: wwang5@uwyo.edu.
} 


\section{Introduction}

It is well known that liquid electrolytes in quantum dot sensitized solar cells (QDSSCs) have issues such as being volatile and corrosive, which cause difficulties in device packaging and decrease the long-term stability of the cells [1]. On the other hand, solid-state electrolytes have been widely studied in the past, and most of the research has been carried out on dye sensitized solar cells (DSSCs) [2]. Research on all solid-state quantum dot sensitized solar cells has attracted more attention recently, and it is expected that the application of solid-state or quasi solid-state electrolytes in QDSSCs could substantially improve their performance by reducing QD corrosion and device degradation as well as realizing a faster hole regeneration [3]. Typical all solid-state QDSSCs are based on mesoporous $\mathrm{TiO}_{2}$ nanoparticle films, $\mathrm{CdSe}$ or PbS QD sensitizers, and solid-state hole conductors such as spiro-OMeTAD [1]. However, one major issue with most solid-state hole transporting materials is the poor penetration into mesoporous photoanode thin films, which limits film thickness and lowers the light harvesting efficiency. In this study we investigate polymer-based solid-state electrolytes for QDSSCs, which have the advantages of easy penetration into porous films, good wettability with the nanostructured photoanodes, and relatively high ionic conductivity [4]. Polymer electrolytes have been inspected for different applications in the past, such as in Lithium ion batteries or DSSCs [5]. However, to the best of our knowledge, thus far there are only limited reports on their applications in QDSSCs [6].

39 Typical liquid electrolytes used for QDSSCs are aqueous polysulfide solutions with the

$40 \mathrm{~S}^{2-} / \mathrm{S}_{\mathrm{x}}{ }^{2-}$ redox couple [7-9], and this redox couple plays a key role in the regeneration of the 
41 semiconductor QDs by scavenging the photogenerated holes [10]. In such liquid electrolytes,

42 the oxidization at the photoanode/electrolyte interface can be described as $[11,12]$ :

60

$$
\begin{gathered}
\mathrm{S}^{2-}+2 \mathrm{~h}^{+} \rightarrow \mathrm{S} \\
\mathrm{S}+\mathrm{S}_{\mathrm{x}-1}{ }^{2-} \rightarrow \mathrm{S}_{\mathrm{x}}{ }^{2-}
\end{gathered}
$$

$\mathrm{S}_{\mathrm{x}}{ }^{2-}$ is then reduced to $\mathrm{S}^{2-}$ at the counter electrode in the regeneration process [13]:

$$
\mathrm{S}_{\mathrm{x}}^{2-}+2 \mathrm{e}^{-} \rightarrow \mathrm{S}_{\mathrm{x}-1}{ }^{2-}+\mathrm{S}^{2-}
$$

Popular redox additives used to generate the $\mathrm{S}^{2-} / \mathrm{S}_{\mathrm{x}}{ }^{2-}$ redox couple in liquid electrolytes include $\mathrm{S} / \mathrm{Na}_{2} \mathrm{~S}$ in water [14], $\mathrm{Na}_{2} \mathrm{~S}$ in alkaline aqueous solution [15], and recently reported $\left[\left(\mathrm{CH}_{3}\right)_{4} \mathrm{~N}\right]_{2} \mathrm{~S} / \mathrm{S}$ in organic solvent [16]. However, for polymer-based solid-state electrolytes thus far there are only limited studies of new types of redox additives [17]. In this work, we utilize S/tetramethylammonium sulfate (S/TMAS) as the redox additive to create polymer electrolytes based on Poly(ethylene oxide)-Poly(vinylidene fluoride) (PEO-PVDF). Their properties are characterized and are compared with those of the polymer electrolytes with the $\mathrm{S} / \mathrm{Na}_{2} \mathrm{~S}$ redox additive. QDSSCs are also fabricated using these polymer electrolytes, and the incident photon-to-current conversion efficiency (IPCE) measurement results show that the new type of polymer electrolyte with the S/TMAS redox additive can improve the solar cell IPCE and enhance their stability.

\section{Experimental methods}

\subsection{Sample preparation}

Poly(ethylene oxide) (PEO, $M_{\mathrm{w}}=4 \times 10^{5} \mathrm{~g} / \mathrm{mol}$, Sigma-Aldrich, St. Louis, MO, USA), 

$\left[\left(\mathrm{CH}_{3}\right)_{4} \mathrm{~N}\right]_{2} \mathrm{SO}_{4}, 99 \%$, Fluka, Sigma-Aldrich, St. Louis, MO, USA), sulfur powder (S, 99.5\%, Alfa Aesar, Ward Hill, MA, USA), propylene carbonate (PC, Sigma-Aldrich), 1,2-dimethoxyethane (DME, Sigma-Aldrich), $\mathrm{TiO}_{2}(\mathrm{P} 25,20-30 \mathrm{~nm}$, Acros Organics, Thermo Fisher, Waltham, MA, USA), zinc nitrate hydrate $\left(\mathrm{Zn}(\mathrm{Ac})_{2} \cdot 2 \mathrm{H}_{2} \mathrm{O}, 99 \%\right.$, Alfa Aesar), sodium sulfide nonahydrate $\left(\mathrm{Na}_{2} \mathrm{~S} \cdot 9 \mathrm{H}_{2} \mathrm{O}, 98 \%\right.$, Sigma-Aldrich), cadmium nitrate tetrahydrate $\left(\mathrm{Cd}\left(\mathrm{NO}_{3}\right)_{2} \cdot 4 \mathrm{H}_{2} \mathrm{O}, 98 \%\right.$, Sigma-Aldrich), selenium dioxide $\left(\mathrm{SeO}_{2}, 99.9 \%\right.$, Sigma-Aldrich), and sodium borohydride $\left(\mathrm{NaBH}_{4}, 99 \%\right.$, Fluka) were used in this study. 

dissolved in $15 \mathrm{~g}$ of DME/PC (3:7, v/v) co-solvent under continuous stirring at $80{ }^{\circ} \mathrm{C}$ for $4 \mathrm{~h}$ in a water bath. Solid $\mathrm{S}$ and TMAS with different S/TMAS molar ratios $(0.3,0.7,1.3,2,3,4,5,7$, 11, and 14) were then added at room temperature, during which the total mass of S and TMAS was kept at $0.0488 \mathrm{~g}$. The electrolyte solution was then stirred for 5 days to form a homogeneous viscous liquid. PEO-PVDF polymer electrolytes with pure $\mathrm{S}$, pure TMAS, or $\mathrm{S} / \mathrm{Na}_{2} \mathrm{~S}\left(\mathrm{~S} / \mathrm{Na}_{2} \mathrm{~S}\right.$ molar ratio of 3 with a total mass of 0.0488

g) were also prepared for comparison studies, and the preparation procedure is similar.

To fabricate solid-state QDSSCs, the polymer electrolyte solution was applied on the electrolyte/photoanode assembly. The device was further stored in the oven at $80{ }^{\circ} \mathrm{C}$ for solid-state QDSSC was created.

99 
using the transmission mode. The ionic conductivity of the polymer electrolyte was measured using a Compact Stat.e10800 Electrochemical Analyzer (Ivium) from $1 \mathrm{~Hz}$ to $1 \mathrm{MHz}$ with a signal amplitude of $10 \mathrm{mV}$. IPCE was measured under $100 \mathrm{~W}$ Quartz Tungsten lamp with an Oriel 1/8 m Comerstone Monochromator (Newport Corporation, Irvine, CA, USA) from 340 - $800 \mathrm{~nm}$, and the lock-in technique was used to acquire the photocurrent at short-circuit condition. Stability tests of the QDSSCs were carried out at different aging times without device sealing. The IPCE measurements were conducted under ambient conditions, and after each measurement the samples were kept in a dark storage unit at room temperature.

\section{Results and discussion}

\subsection{Morphology of PEO-PVDF electrolytes with S/TMAS and $\mathrm{S} / \mathrm{Na}_{2} \mathrm{~S}$ additives}

Fig. 1a and $\mathrm{b}$ show scanning electron microscopy images of PEO-PVDF electrolyte membranes with the S/TMAS and $\mathrm{S} / \mathrm{Na}_{2} \mathrm{~S}$ redox additives, respectively, and in both electrolytes the sulfur concentration is $0.02 \mathrm{M}$ (the molar ratio of S/TMAS or $\mathrm{S} / \mathrm{Na}_{2} \mathrm{~S}$ is 3). It can be seen from Fig. 1 that the electrolyte film with the S/TMAS redox additive exhibits a smooth and continuous surface morphology, while the electrolyte film with the $\mathrm{S} / \mathrm{Na}_{2} \mathrm{~S}$ additive displays a surface with rough aggregates and pores.

\subsection{UV-Vis absorption study of PEO-PVDF polymer electrolytes with different redox} additives and S/TMAS molar ratios

Fig. 2a shows the UV-Vis absorption spectra of the PEO-PVDF polymer electrolytes with S, 
S/TMAS $[\mathrm{M}(\mathrm{S})=0.02 \mathrm{M}, \mathrm{S} / \mathrm{TMAS}$ molar ratio $=3]$, and $\mathrm{S} / \mathrm{Na}_{2} \mathrm{~S}\left[\mathrm{M}(\mathrm{S})=0.02 \mathrm{M}, \mathrm{S} / \mathrm{Na}_{2} \mathrm{~S}\right.$ molar ratio $=3$ ] additives. The electrolytes exhibit absorption bands around 218 and $264 \mathrm{~nm}$, which correspond to the absorption of thiosulfate $\mathrm{S}_{2} \mathrm{O}_{3}{ }^{2-}$ and polysulfide $\mathrm{S}_{\mathrm{x}}{ }^{2-}$, respectively $[18,19]$. In the PEO-PVDF electrolyte with $\mathrm{S} / \mathrm{Na}_{2} \mathrm{~S}$, the formation of $\mathrm{S}_{\mathrm{x}}{ }^{2-}$ is attributed to the following reactions [18]:

$$
\begin{aligned}
& \mathrm{Na}_{2} \mathrm{~S}+\mathrm{H}_{2} \mathrm{O} \leftrightharpoons 2 \mathrm{Na}^{+}+\mathrm{HS}^{-}+\mathrm{OH}^{-} \\
& (\mathrm{x}-1) \mathrm{S}+\mathrm{HS}^{-}+\mathrm{OH}^{-} \rightarrow \mathrm{S}_{\mathrm{x}}{ }^{2-}+\mathrm{H}_{2} \mathrm{O}
\end{aligned}
$$

In the electrolyte with $\mathrm{S}$ but without $\mathrm{Na}_{2} \mathrm{~S}, \mathrm{~S}_{\mathrm{x}}{ }^{2-}$ can be formed differently according to previously published studies related to the hydrolysis reaction of zero-valent sulfur and sulfide oxidation in weakly acidic solutions [20-22]:

$$
\begin{aligned}
& 4 \mathrm{~S}^{(0)}+4 \mathrm{H}_{2} \mathrm{O} \rightarrow 3 \mathrm{H}_{2} \mathrm{~S}+\mathrm{HSO}_{4}{ }^{-}+\mathrm{H}^{+} \\
& \mathrm{H}_{2} \mathrm{~S} \leftrightharpoons \mathrm{HS}^{-}+\mathrm{H}^{+} \\
& \mathrm{HS}^{-}+(\mathrm{x}-1) \mathrm{S} \rightarrow \mathrm{H}^{+}+\mathrm{S}_{\mathrm{x}}{ }^{2-}
\end{aligned}
$$

In the PEO-PVDF electrolyte with S/TMAS, $\mathrm{S}_{\mathrm{x}}{ }^{2-}$ can also be formed from the $\mathrm{S}$ content as described in eq. (6) - (8). In Fig. 2a, the PEO-PVDF polymer electrolytes with S or S/TMAS exhibit obvious absorption band of thiosulfate $\mathrm{S}_{2} \mathrm{O}_{3}{ }^{2-}$ at $\sim 218 \mathrm{~nm}$, and the electrolyte with $\mathrm{S} / \mathrm{Na}_{2} \mathrm{~S}$ also shows a weak absorption peak at this wavelength. The formation of $\mathrm{S}_{2} \mathrm{O}_{3}{ }^{2-}$ in the electrolytes is due to the fact that polysulfide is highly reactive and undergoes rapid oxidation reaction with oxygen [22]:

$$
\mathrm{S}_{\mathrm{x}}{ }^{2-}+3 / 2 \mathrm{O}_{2} \rightarrow \mathrm{S}_{2} \mathrm{O}_{3}^{2-}+(\mathrm{x}-2) \mathrm{S}
$$

The preparation of the PEO-PVDF electrolytes in air and a water bath $\left(80{ }^{\circ} \mathrm{C}\right)$ makes it easy for water and oxygen to react with $\mathrm{S}$, and the reactions proceed as discussed above, which 
produce $\mathrm{S}_{2} \mathrm{O}_{3}{ }^{2-}$ and $\mathrm{S}_{\mathrm{x}}{ }^{2-}$ in the electrolytes. From Fig. 2a it also can be seen that the addition of TMAS in the electrolyte increases the absorption intensity of $\mathrm{S}_{2} \mathrm{O}_{3}{ }^{2-}$. In organic synthesis, quaternary ammonium salts are typically utilized as phase transfer catalysts, which can accelerate the reactions between reagents dissolved in immiscible solvents [23]. Therefore, the effect of TMAS on $\mathrm{S}_{2} \mathrm{O}_{3}{ }^{2-}$ absorption intensity indicates that it plays the role of a catalyst in the electrolyte to promote the formation of $\mathrm{S}_{2} \mathrm{O}_{3}{ }^{2-}$.

Fig. 2b shows the UV-Vis absorption spectra of the PEO-PVDF polymer electrolytes with different S/TMAS molar ratios, and the inset shows the influence of the S/TMAS molar ratio on the absorption intensity at 218 and $264 \mathrm{~nm}$ that are associated with $\mathrm{S}_{2} \mathrm{O}_{3}{ }^{2-}$ and $\mathrm{S}_{\mathrm{x}}{ }^{2-}$, respectively. It can be seen that increasing the S/TMAS molar ratio in the electrolytes leads to increased absorption of $\mathrm{S}_{2} \mathrm{O}_{3}{ }^{2-}$ and $\mathrm{S}_{\mathrm{x}}{ }^{2-}$. The enhanced absorption of $\mathrm{S}_{\mathrm{x}}{ }^{2-}$ can be attributed to the increased $\mathrm{S}$ concentration in the electrolytes when the S/TMAS molar ratio becomes larger, which promotes the reactions described in eq. (6) - (8). According to eq. (9), this increase in $\mathrm{S}_{\mathrm{x}}{ }^{2-}$ concentration further causes an increase in $\mathrm{S}_{2} \mathrm{O}_{3}{ }^{2-}$ concentration, and hence an increase in the absorption intensity of $\mathrm{S}_{2} \mathrm{O}_{3}{ }^{2-}$ as shown in Fig. 2b [21].

\subsection{Solid-State QDSSCs based on PEO-PVDF polymer electrolytes with S/TMAS and S/Na $\mathrm{S}_{2}$} redox additives

It has been confirmed that the sulfide ion $\mathrm{S}^{2-}$ is only formed in strong alkaline $\mathrm{Na}_{2} \mathrm{~S}$ solution (e.g., $\left.\mathrm{M}\left(\mathrm{OH}^{-}\right)=18 \mathrm{M}\right)$, and the $\mathrm{UV}-\mathrm{Vis}$ absorption band of $\mathrm{S}^{2-}$ is around $250 \mathrm{~nm}$ [24]. In most electrolytes with $\mathrm{S} / \mathrm{Na}_{2} \mathrm{~S}$ in aqueous solution or in organic solvent that contains water, the sulfide ion $\mathrm{S}^{2-}$ exists predominantly as $\mathrm{HS}^{-}$and the frequently referred $\mathrm{S}^{2-} / \mathrm{S}_{\mathrm{x}}{ }^{2-}$ redox couple is 
in fact $\mathrm{HS}^{-} / \mathrm{S}_{\mathrm{x}}{ }^{2-}$ [25]. For the PEO-PVDF polymer electrolytes with the S/TMAS or $\mathrm{S} / \mathrm{Na}_{2} \mathrm{~S}$ additives studied in this work, the absorption bands of either $\mathrm{HS}^{-}$at $\sim 230 \mathrm{~nm}$ or $\mathrm{S}^{2-}$ at $\sim 250$ $\mathrm{nm}$ are not observed in the UV-Vis spectra shown in Fig. 2, indicating that their concentrations in the electrolytes are insignificant [18]. Based on this observation, in addition to the redox circle that is described by eq. (1) - (3), there could be another possible redox circle in the QDSSCs prepared with the PEO-PVDF polymer electrolytes with S/TMAS or $\mathrm{S} / \mathrm{Na}_{2} \mathrm{~S}$ redox additives. This additional redox process is illustrated in Schematic 1. In the PEO-PVDF electrolyte with S/TMAS, $S$ works as the source to form $S_{x}{ }^{2-}$ as suggested in eq. (6) - (8), and TMAS acts as the catalyst to promote the formation of $\mathrm{S}_{\mathrm{x}}{ }^{2-}$. While in the PEO-PVDF electrolyte with $\mathrm{S} / \mathrm{Na}_{2} \mathrm{~S}$, both $\mathrm{S}$ and $\mathrm{Na}_{2} \mathrm{~S}$ can serve as the source to form $\mathrm{S}_{\mathrm{x}}{ }^{2-}$ by hydrolysis reactions as suggested in eq. (4) - (8). In the PEO-PVDF electrolyte with either S/TMAS or $\mathrm{S} / \mathrm{Na}_{2} \mathrm{~S}, \mathrm{~S}_{2} \mathrm{O}_{3}{ }^{2-}$ can be formed by oxidation of the polysulfide ions in the electrolyte as described by eq. (9) [21]. $\mathrm{S}_{2} \mathrm{O}_{3}{ }^{2-}$ can act as an oxidizing agent that traps electrons at the electrolyte/counter electrode interface and produces $S^{2-}$ in the electrolyte as shown in Schematic 1 [26]. Meanwhile, the excess polysulfide ions $S_{x}{ }^{2-}$ can also serves as the electron scavenger at the electrolyte/counter electrode interface. While at the $\mathrm{TiO}_{2} /$ electrolyte interface the holes are removed by $\mathrm{S}^{2-}$, and the whole redox process in the PEO-PVDF polymer electrolytes can then be described by [18,20-22,26]:

$$
\begin{gathered}
\mathrm{S}_{2} \mathrm{O}_{3}{ }^{2-}+2 \mathrm{e}^{-} \rightarrow \mathrm{S}^{2-}+\mathrm{SO}_{3}{ }^{2-} \\
\mathrm{S}_{\mathrm{x}}{ }^{2-}+2 \mathrm{e}^{-} \rightarrow \mathrm{S}_{\mathrm{x}-1}{ }^{2-}+\mathrm{S}^{2-} \\
\mathrm{S}^{2-}+2 \mathrm{~h}^{+} \rightarrow \mathrm{S} \\
\mathrm{S}+\mathrm{S}_{\mathrm{x}-1}{ }^{2-} \rightarrow \mathrm{S}_{\mathrm{x}}{ }^{2-}
\end{gathered}
$$


3.4 Ionic conductivity of PEO-PVDF electrolytes with different redox additives and S/TMAS

molar ratios

Fig. 3a shows the ionic conductivity of the PEO-PVDF polymer electrolytes with different redox additives of S/TMAS $[\mathrm{M}(\mathrm{S})=0.02 \mathrm{M}, \mathrm{S} / \mathrm{TMAS}$ molar ratio $=3]$ and $\mathrm{S} / \mathrm{Na}_{2} \mathrm{~S}[\mathrm{M}(\mathrm{S})=$ $0.02 \mathrm{M}, \mathrm{S} / \mathrm{Na}_{2} \mathrm{~S}$ molar ratio $=3$ ]. It can be seen that the ionic conductivity of the electrolyte with S/TMAS is significantly higher than that of the electrolyte with $\mathrm{S} / \mathrm{Na}_{2} \mathrm{~S}$. This increased ionic conductivity can be attributed to the smoother and more continuous surface morphology of the S/TMAS modified PEO-PVDF electrolyte as shown in Fig. 1, which is expected to form efficient ion transport channels in the electrolyte and results in a faster ion transport [27]. In addition, the higher anion concentration in the PEO-PVDF-S/TMAS electrolyte, as suggested by Fig. 2a, can also contribute to this conductivity improvement [28].

Fig. $3 b$ shows the dependence of the ionic conductivity of the PEO-PVDF-S/TMAS electrolytes on S/TMAS molar ratio. The ionic conductivity of the electrolyte with an S/TMAS molar ratio of 0.3 is $0.13 \mathrm{mS} \cdot \mathrm{cm}^{-1}$. When the S/TMAS molar ratio is increased, an improvement in the ionic conductivity is observed, with the maximum value of $0.63 \mathrm{mS} \cdot \mathrm{cm}^{-1}$ obtained for the electrolyte with an S/TMAS molar ratio of 3. However, further increasing the molar ratio beyond 3 causes a decrease in the ionic conductivity of the electrolytes.

ATR-FTIR measurements were carried out in order to better understand the interactions between different components in the synthesized polymer electrolytes as well as the ionic conductivity change. Fig. 4 shows the ATR-FTIR spectra of PEO-PVDF, PEO-PVDF-S, PEO-PVDF-TMAS, PEO-PVDF-S/Na $2 \mathrm{~S}\left(\mathrm{~S} / \mathrm{Na}_{2} \mathrm{~S}\right.$ molar ratio = 3), and PEO-PVDF-S/TMAS 
with different S/TMAS molar ratios. Fig. $4 a, 4 b$, and 4c exhibit these ATR-FTIR spectra in the wavelength range of $4000-400 \mathrm{~cm}^{-1}, 1050-910 \mathrm{~cm}^{-1}$, and $650-550 \mathrm{~cm}^{-1}$, respectively. The absorption bands at $3300-3500,2885,1404$, and $1100 \mathrm{~cm}^{-1}$ in Fig. $4 \mathrm{a}$ are assigned to the vibration modes of $v(\mathrm{OH}), v(\mathrm{CH}), v(\mathrm{CF})$, and $v(\mathrm{COC})$ in the PEO-PVDF polymer matrix, respectively [29]. The asymmetric stretching mode of $v\left(\mathrm{C}_{4} \mathrm{~N}\right)$ from the TMAS molecules also appears at $\sim 948 \mathrm{~cm}^{-1}$ in the spectrum of the PEO-PVDF-TMAS polymer film [30]. However, it can be seen from Fig. $4 \mathrm{~b}$ and $4 \mathrm{c}$ that new absorption bands are formed at wavelengths of 1023 and $614 \mathrm{~cm}^{-1}$, which only show up in the spectra of the PEO-PVDF-S/TMAS and PEO-PVDF-S/Na $2 \mathrm{~S}$ polymer electrolytes. As discussed above, thiosulfate anion $\mathrm{S}_{2} \mathrm{O}_{3}{ }^{2-}$ is formed in the PEO-PVDF polymer electrolytes with $\mathrm{S} / \mathrm{TMAS}$ or $\mathrm{S} / \mathrm{Na}_{2} \mathrm{~S}$ redox additives. This anion is subjected to cross-linking with cations, and the $\left[\left(\mathrm{CH}_{3}\right)_{4} \mathrm{~N}\right]^{+}$ion in TMAS and the $\mathrm{Na}^{+}$ ion in $\mathrm{Na}_{2} \mathrm{~S}$ may interact with $\mathrm{S}_{2} \mathrm{O}_{3}{ }^{2-}$ and form amine-sulfate intermediate complexes such as $\left[\left(\mathrm{CH}_{3}\right)_{4} \mathrm{~N}\right]^{+} \cdots \mathrm{S}_{-} \mathrm{SO}_{3}{ }^{2-}$ and $\mathrm{Na}^{+} \cdots \mathrm{S}_{-} \mathrm{SO}_{3}{ }^{2-}$ in the PEO-PVDF-S/TMAS and PEO-PVDF-S/Na $2 \mathrm{~S}$ electrolytes, respectively [31,32]. Based on previously studies, the new absorption bands at 1023 and $614 \mathrm{~cm}^{-1}$ can be associated with the absorption of $v\left(\mathrm{SO}_{3}\right)$ in the intermediate complexes [32]. As can be seen from Fig. $4 \mathrm{~b}$ and $4 \mathrm{c}$, when the S/TMAS molar ratio is increased, the absorption intensities of $v\left(\mathrm{SO}_{3}\right)$ at 1023 and $614 \mathrm{~cm}^{-1}$ also increase, indicating an increased number of newly formed amine-sulfate intermediate complexes. This increase in the amine-sulfur intermediate complexes can reduce the amount of free, moveable cations/anions in the electrolyte, which can decrease the ionic conductivity. Therefore, in Fig. $3 b$ the increase in the ionic conductivity with increased S/TMAS molar ratio in the range of 0.3 - 3 can be associated with the increased anion concentration as discussed previously. 
However, when the S/TMAS molar ratio is further increased, the increased formation of intermediate complexes surpasses the anion concentration increase and leads to decreased ionic conductivity. In addition, when the S/TMAS molar ratio becomes larger, sulfur aggregation is expected to happen due to limited sulfur solubility in the organic solvent and the viscosity of the polymer electrolyte is expected to rise, which can be another factor that causes the ionic conductivity decrease. and PEO-PVDF-S/TMAS (S/TMAS molar ratio = 3) electrolytes, especially from Fig. 4c,

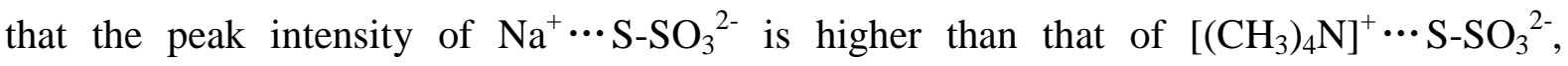
suggesting a higher number of intermediate complexes in the PEO-PVDF-S/ $\mathrm{Na}_{2} \mathrm{~S}$ electrolyte than that in the PEO-PVDF-S/TMAS (S/TMAS molar ratio = 3) electrolyte. In addition to the contribute to the lower ionic conductivity of the PEO-PVDF-S/ $\mathrm{Na}_{2} \mathrm{~S}$ electrolyte. electrolytes and stability test with the polymer electrolytes exhibit comparable or improved IPCE performance, and the cell prepared with the PEO-PVDF-S/TMAS electrolyte especially shows much higher IPCE 
in the wavelength region of $340-550 \mathrm{~nm}$. Fig. 5b shows the IPCE spectra of the QDSSCs prepared with the PEO-PVDF-S/TMAS electrolytes with different S/TMAS molar ratios, and the inset shows the maximum IPCE of the cells at $340 \mathrm{~nm}$ as a function of the S/TMAS molar ratio. It can be seen from this figure that increasing the S/TMAS molar ratio from 0.3 to 3 leads to a substantial increase in the maximum IPCE value, however further increasing this ratio beyond 3 causes a decrease in the IPCE value. This observation is consistent with the ionic conductivity measurement result that is shown in Fig. 3b. As reported previously, higher ionic conductivity generally corresponds to faster ion transport in the electrolyte, which facilitates the redox cycle and results in higher IPCE [33, 34].

Stability tests were also conducted to compare the performance of the QDSSCs prepared with liquid and polymer electrolytes. Fig. 5c shows the normalized IPCE of the QDSSC prepared with the liquid $\mathrm{S} / \mathrm{Na}_{2} \mathrm{~S}$ electrolyte, while Fig. $5 \mathrm{~d}$ shows the normalized IPCE of the cell prepared with the PEO-PVDF-S/TMAS electrolyte with an S/TMAS molar ratio of 3, and the insert in Fig. 5d shows the normalized IPCE at $340 \mathrm{~nm}$ as a function of the aging time. It polymer electrolyte with the S/TMAS redox additive.

\section{Conclusions}


284 In this work polymer electrolytes based on PEO-PVDF with S/TMAS and $\mathrm{S} / \mathrm{Na}_{2} \mathrm{~S}$ redox 285 additives are investigated. UV-Vis and ionic conductivity measurements are performed to 286 characterize their optical and electrochemical properties. QDSSCs are fabricated using the 287 polymer electrolytes, and a possible additional redox process in the cells is proposed. The 288 QDSSCs with the PEO-PVDF-S/TMAS electrolytes exhibit improved IPCE and device 289 stability compared to the cell with liquid electrolyte. This research could provide important 290 insights into the study of novel polymer electrolytes for energy harvesting and storage 291 applications.

292

293 Acknowledgment. This work was supported by the U.S. Department of Energy, Office of 294 Basic Energy Sciences, Division of Materials Sciences and Engineering under Award 295 DE-FG02-10ER46728.

296

297 


\section{References}

[1] P. Ardalan, T.P. Brennan, H. Lee, J.R. Bakke, I. Ding, M.D. McGehee, S.F. Bent, ACS Nano 5 (2011) 1495.

[2] I.K. Ding, N. Tetreault, J. Brillet, B.E. Hardin, E.H. Smith, S.J. Rosenthal, F. Sauvage, M. Grätzel, M. McGehee, Adv. Funct. Mater. 19 (2009) 2431.

[3] H. Lee, H.C. Leventis, S. Moon, P. Chen, S. Ito, S.A. Haque, T. Torres, F. Nu“esch, T. Geiger, S.M. Zakeeruddin, M. Grätzel, M. Nazeeruddin, Adv. Funct. Mater. 19 (2009) 2735. [4] J. Kang, W. Li, X. Wang, Y. Lin, X. Xiao, S. Fang, Electrochim. Acta, 48 (2003) 2487. [5] A.F. Nogueira, C. Longo, M.A. De Paoli, Coord. Chem. Rev. 248 (2004) 1455.

[6] Z. Yu, Q. Zhang, D. Qin, Y. Luo, D. Li, Q. Shen, T. Toyoda, Q. Meng, Electrochem. Commun. 12 (2010) 1776.

[7] P.V. Kamat, Adv. Funct. Mater. 19 (2009) 805.

[8] J.A. Chang, J.H. Rhee, S.H. Im, Y.H. Lee, H. Kim, S.I. Seok, M.K. Nazeeruddin, M. Grätzel, Nano Lett. 10 (2010) 2609.

[9] V. Chakrapani, K. Tvrdy, P.V. Kamat, J. Am. Chem. Soc. 132 (2010) 1228.

[10] P.V. Kamat, K. Tvrdy, D.R. Baker, J.G. Radich, Chem. Rev. 110 (2010) 6664.

[11] Y.L. Lee, Y.S. Lo, Adv. Funct. Mater. 19 (2009) 604.

[12] Y.L. Lee, C.H. Chang, J. Power Sources 185 (2008) 584.

[13] Y. Tachibana, H.Y. Akiyama, Y. Ohtsuka, T. Torimoto, S. Kuwabata, Chem. Lett. 36 (2007)88.

[14] H.K. Jun, M.A. Careem, A.K. Arof, Renew.Sust. Energ. Rev. 22 (2013) 148.

[15] Q. Dai, J. Chen, L. Lu, J. Tang, W. Wang, App. Phy. Lett. 102 (2013) 203904.

[16] L. Li, X. Yang, J. Gao, H. Tian, J. Zhao, A. Hagfeldt, L. Sun, J. Am. Chem. Soc. 133 (2011) 8458 .

[17] S. Wang, Q.X. Zhang, Y.Z. Xu, D.M. Li, Y.H. Luo, Q.B. Meng, J. Power Sources 224 
(2013) 152.

324

325

326

327

328

329

330

331

332

333

334

335

336

337

338

339

340

341

342

343

344

345

346

347

[18] A.K. Safyan, Int. J. Electrochem. Sci. 7 (2012) 561.

[19] N.S.A. Manan, L. Aldous, Y. Alias, P. Murray, L.J. Yellowlees, M.C. Lagunas, C. Hardacre, J. Phys. Chem. B 115 (2011) 13873.

[20] W.F. Giggenbach, Inorg. Chem. 3 (1974) 1730.

[21] K.Y. Chen, J.C. Morris, Environ. Sci. Technol. 6 (1972) 529.

[22] K.Y. Chen, J.C. Morris, Advances in water pollution research, $5^{\text {th }}$ International Conference on Water Pollution Research, San Francisco, USA, July 27-30, 1970; S.H. Jenkins, Ed.; Pergamon Press: Oxford, New York, 1972.

[23] D. Zhao, H. Ren, J. Wang, Y. Yang, Y. Zhao, Energ. Fuel 21 (2007) 2543.

[24] W. Giggenbach, Inorg. Chem. 7 (1971) 1333.

[25] V. Chakrapani, D. Baker, P.V. Kamat, J. Am. Chem. Soc.133 (2011) 9607.

[26] J.B. Lee, Electrochemistry of $\mathrm{FeSO}_{4}-\mathrm{Na}_{2} \mathrm{~S}_{2} \mathrm{O}_{3}$ and $\mathrm{CuSO}_{4}-\mathrm{Na}_{2} \mathrm{~S}_{2} \mathrm{O}_{3}$ Systems for Template-Assisted Nanowire Synthesis. Ph. D. Thesis, University of California, Berkeley, Fall, 2011.

[27] Y. Yang, C. Zhou, S. Xu, H. Hu, B. Chen, J. Zhang, S. Wu, W. Liu, X. Zhao, J. Power Sources 185 (2008) 1492.

[28] J. P. Sharma, S.S. Sekhon, Solid State Ionics 178 (2007) 439.

[29] Y. Yang, J. Zhang, C. Zhou, S. Wu, S. Xu, W. Liu, H. Han, B. Chen, X.Z. Zhao, J. Phys. Chem. B 112 (2008) 6594.

[30] M. Malchus, M. Jansen, Acta Cryst. B 54 (1998) 494.

[31] B. Scholarly, Sulfuric acids-advances in research and application, Acton, Q. A. Scholarly Edition: Atlanta, Georgia, 2013; pp 7-8.

[32] J. J. Whiting, The Chemistry of Compounds Containing N-O and N-S Bonds, Ph.D. Thesis, McGill University, July, 1970. 
348 [33]M. Kang, K. Ahn, J. Lee, J. Power Sources 180 (2008) 896.

349 [34] S. Yang, H. Kou, H. Wang, K. Cheng, J. Wang, New J. Chem.34 (2010) 313.

350 


\section{Figure captions:}

352

353

Fig. 1. SEM images of PEO-PVDF polymer electrolytes with (a) S/TMAS and (b) $\mathrm{S} / \mathrm{Na}_{2} \mathrm{~S}$ redox additives.

Fig. 2. UV-Vis spectra of the PEO-PVDF polymer electrolytes: (a) With pure S, S/TMAS $[\mathrm{S} / \mathrm{TMAS}$ molar ratio $=3, \mathrm{M}(\mathrm{S})=0.02 \mathrm{M}]$, and $\mathrm{S} / \mathrm{Na}_{2} \mathrm{~S}\left[\mathrm{~S} / \mathrm{Na}_{2} \mathrm{~S}\right.$ molar ratio $=3, \mathrm{M}(\mathrm{S})=0.02$ M]. The insert shows the enlarged PEO-PVDF-S/ $\mathrm{Na}_{2} \mathrm{~S}$ spectrum. (b) With different S/TMAS molar ratios. The insert shows the dependence of the absorption intensity on S/TMAS molar ratio.

Schematic 1. Schematic of the redox process in solid-state QDSSCs based on PEO-PVDF polymer electrolyte with S/TMAS.

Fig. 3. Ionic conductivity of the PEO-PVDF polymer electrolytes (a) with different redox additives and (b) with different S/TMAS molar ratios.

Fig. 4. ATR-FTIR spectra of the PEO-PVDF, PEO-PVDF-S, PEO-PVDF-TMAS, PEO-PVDF-S/Na $2 \mathrm{~S}\left(\mathrm{~S} / \mathrm{Na}_{2} \mathrm{~S}\right.$ molar ratio $\left.=3\right)$, and PEO-PVDF-S/TMAS with different S/TMAS molar ratios in the wavelength range of (a) $4000-400 \mathrm{~cm}^{-1}$, (b) $1050-910 \mathrm{~cm}^{-1}$, and (c) $650-550 \mathrm{~cm}^{-1}$.

Fig. 5. (a) IPCE spectra of the QDSSCs with PEO-PVDF polymer electrolytes with different redox additives and a liquid electrolyte with $\mathrm{S} / \mathrm{Na}_{2} \mathrm{~S}$. (b) IPCE spectra of the QDSSCs with PEO-PVDF-S/TMAS polymer electrolytes with different S/TMAS molar ratios. The insert shows the maximum IPCE value at $340 \mathrm{~nm}$ as a function of the S/TMAS molar ratio. (c) Normalized IPCE of the QDSSC with $1 \mathrm{M}$ liquid $\mathrm{S} / \mathrm{Na}_{2} \mathrm{~S}$ electrolyte. (d) Normalized IPCE of the QDSSC with the PEO-PVDF-S/TMAS polymer electrolyte with an S/TMAS molar ratio of 
373 3. The insert shows the normalized IPCE at $340 \mathrm{~nm}$ as a function of the aging time. 
Fig. 2
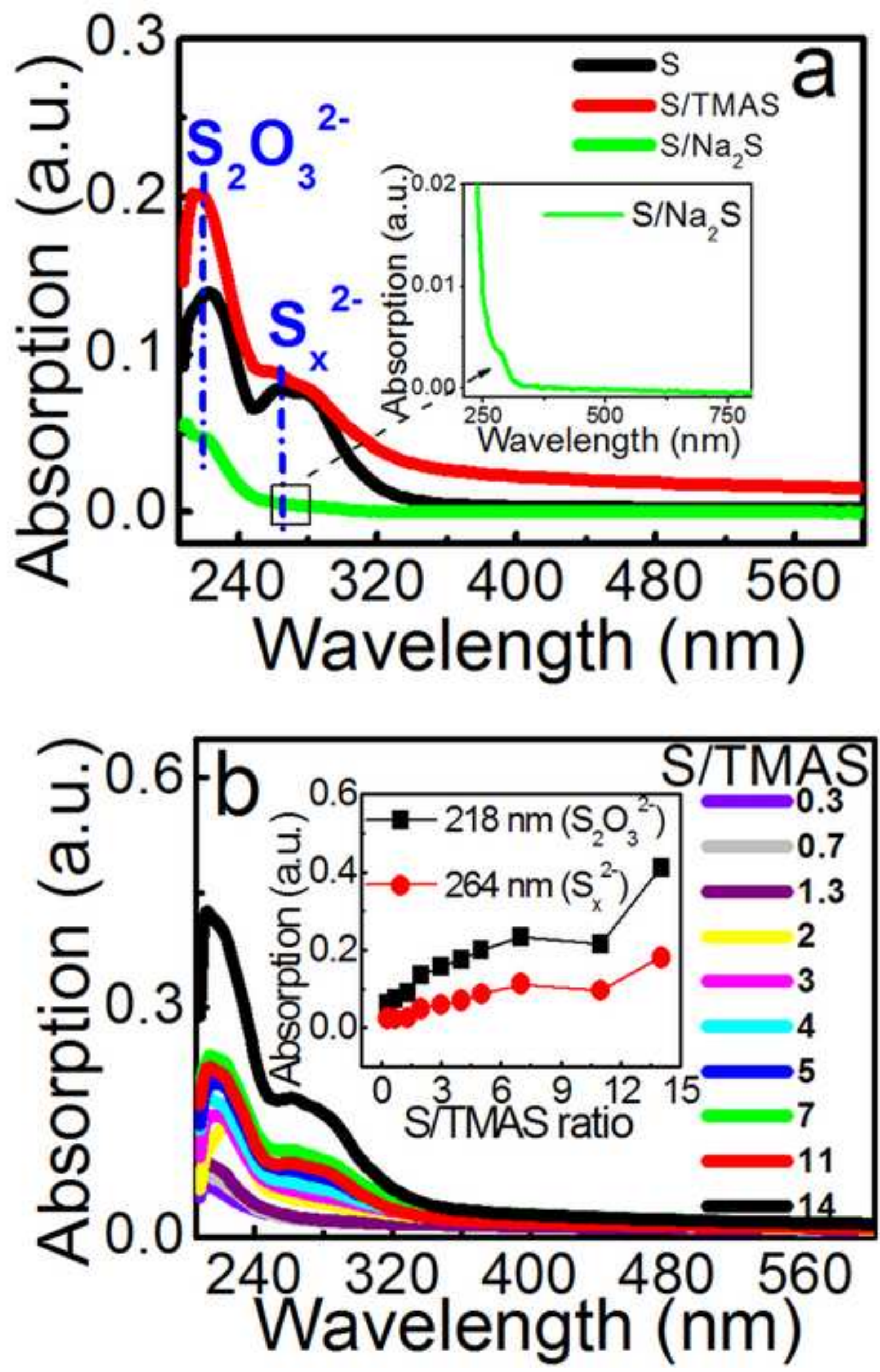


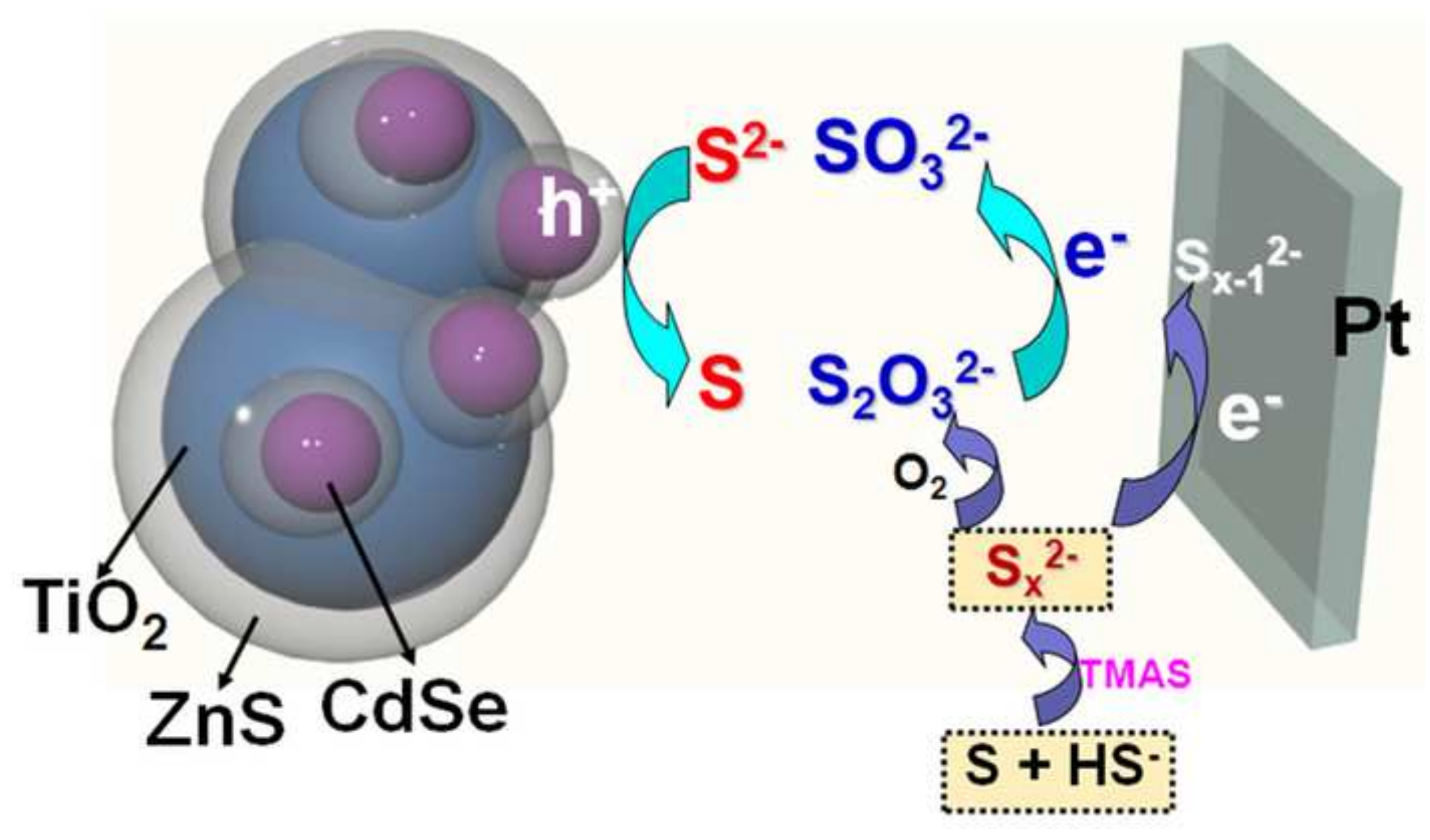



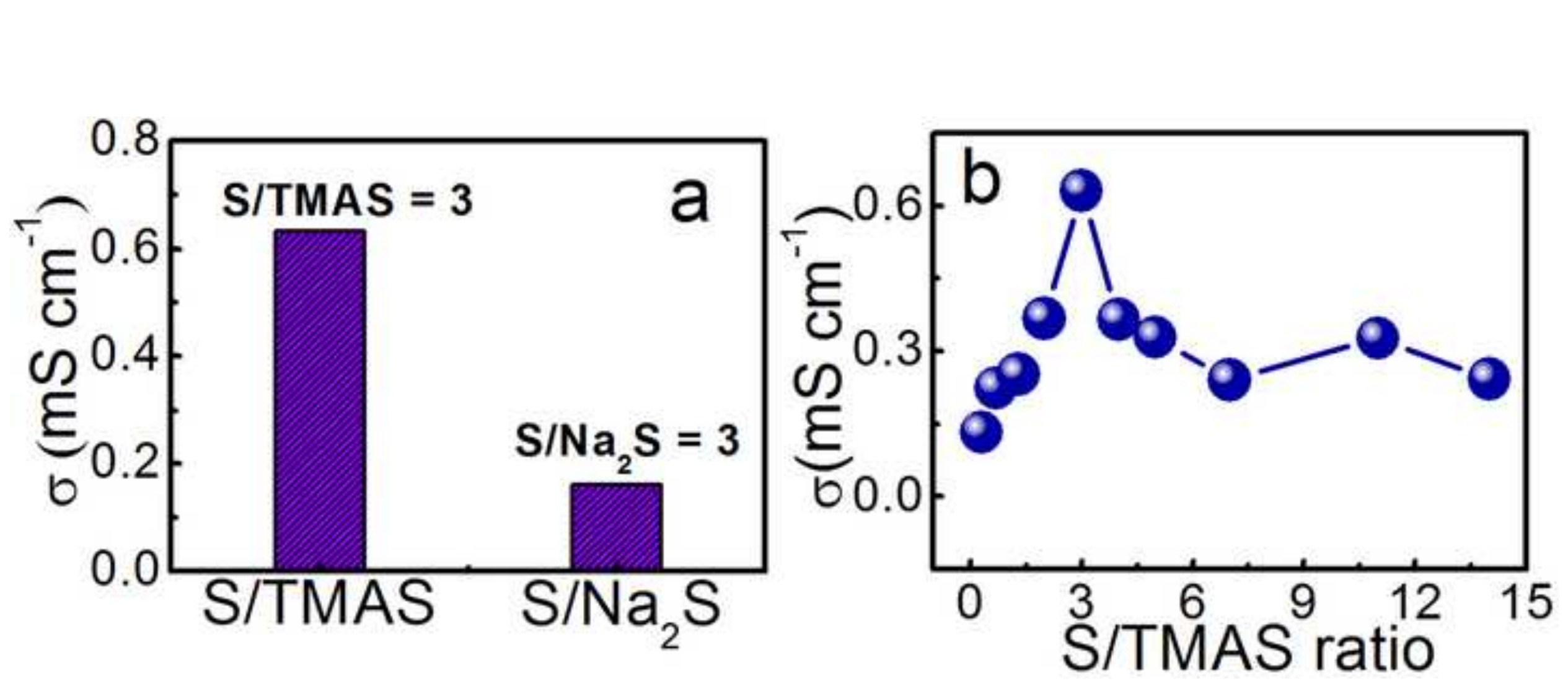
Fig. 4
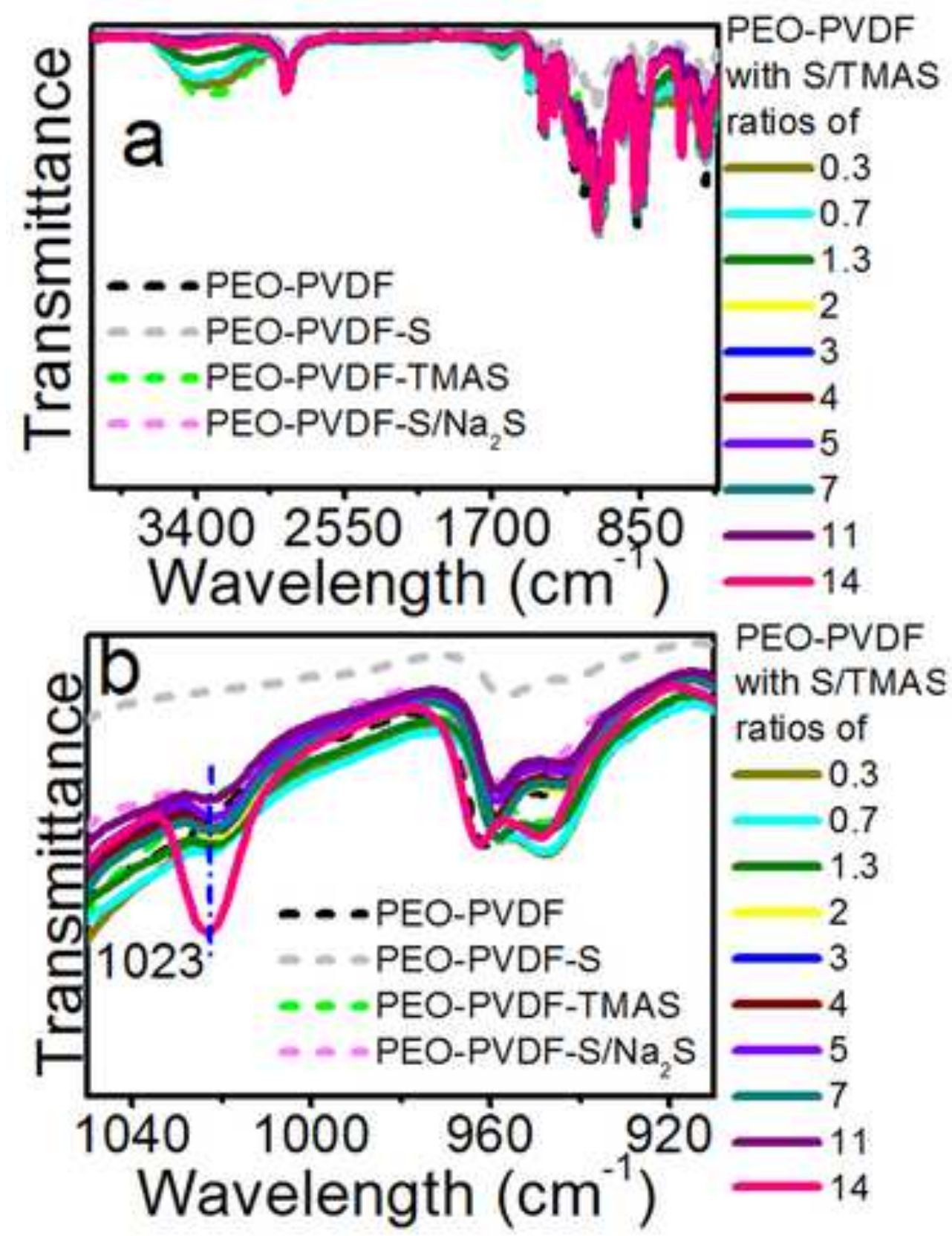

PEO-PVDF with S/TMAS ratios of 0.3

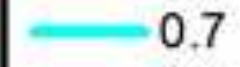

$-1.3$ 2
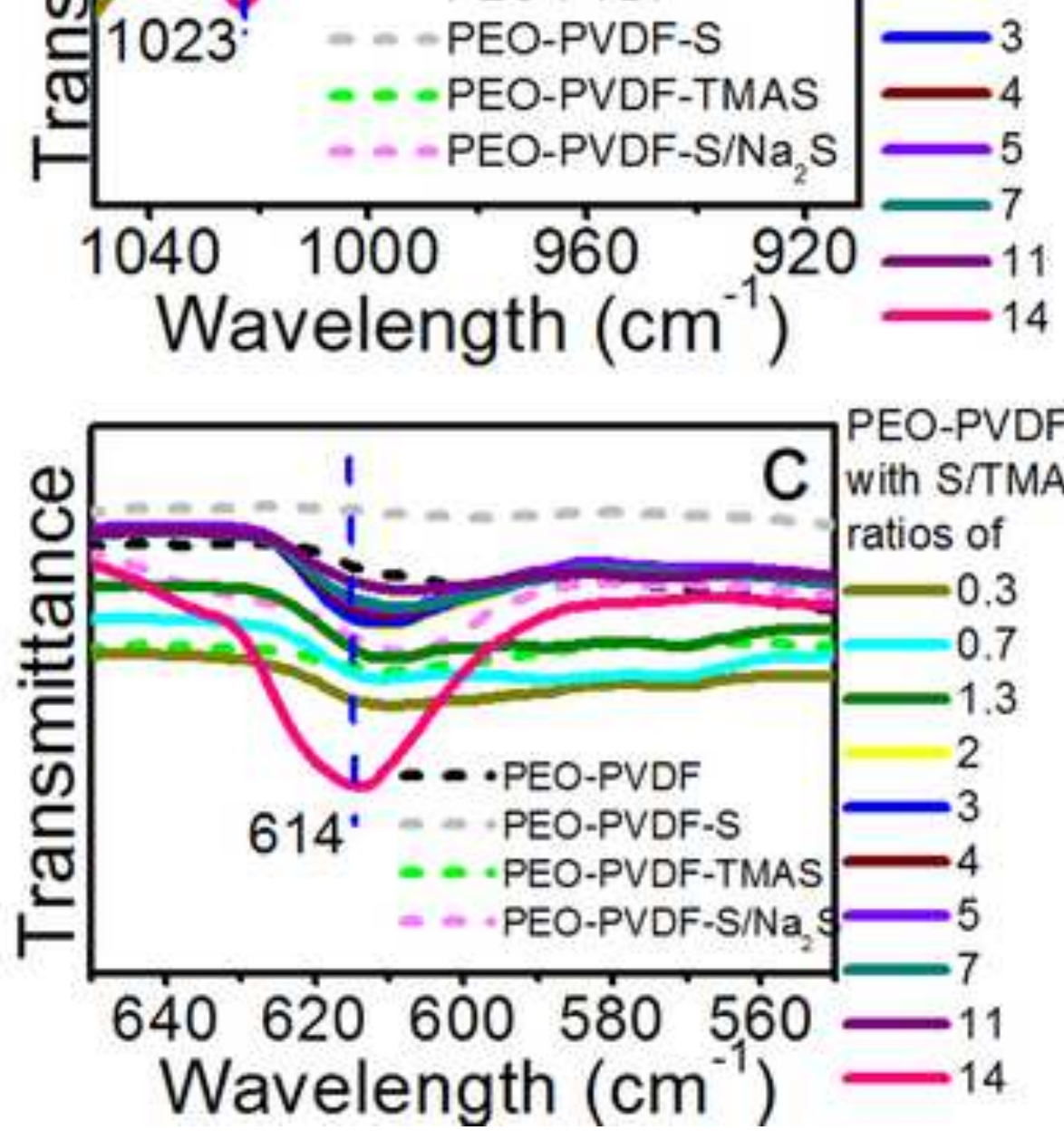

PEO-PVDF with $\mathrm{S} / \mathrm{TMAS}$ ratios of 0.3 

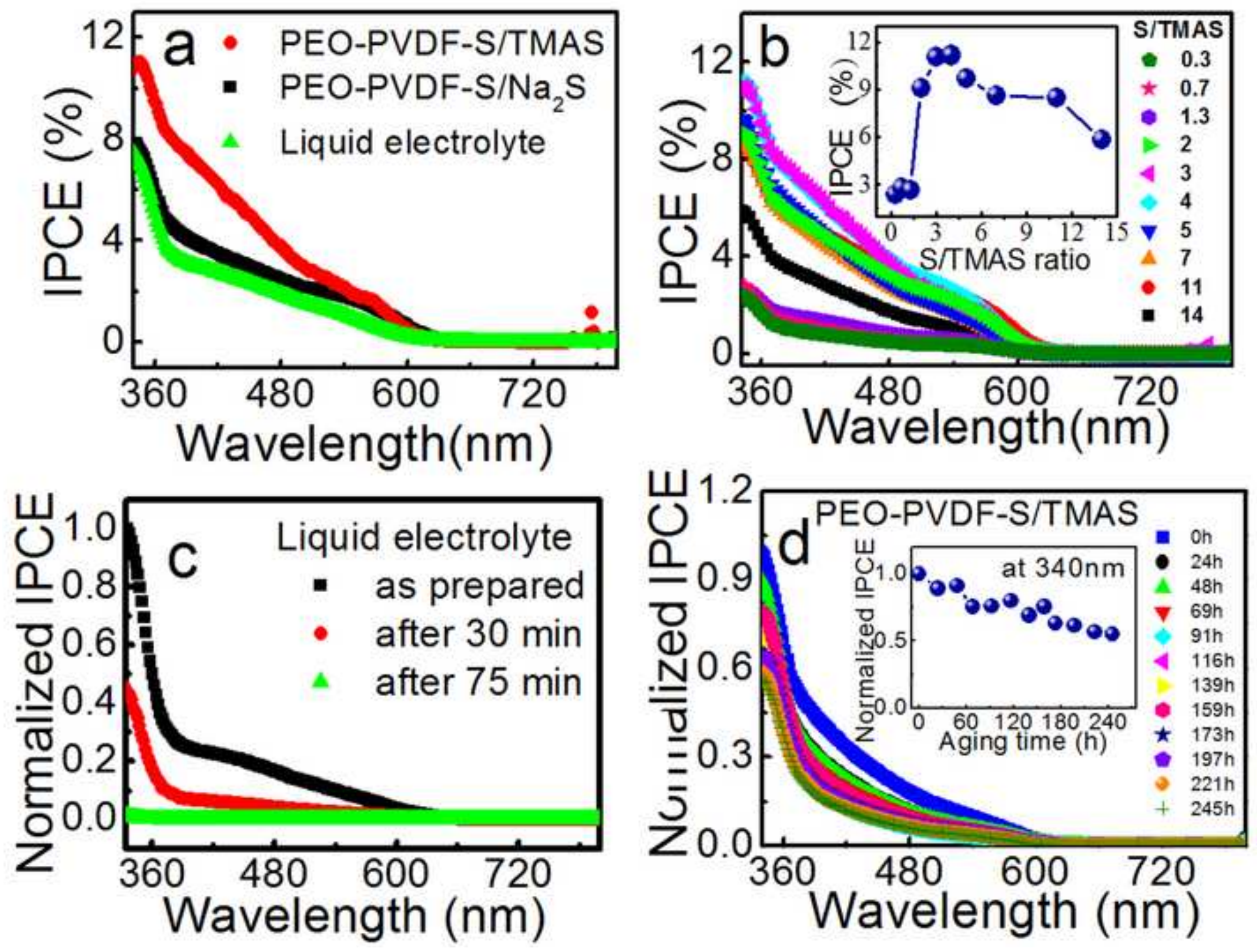